\title{
Istilah-Istilah dalam Upacara Minum Teh Jepang Chanoyu (Suatu Kajian Etnolinguistik)
}

\author{
Terms in the Chanoyu Japanese Tea Drinking Ceremony (An Ethnolinguistics Study)
}

\author{
Irzam Sarif S. ${ }^{1, *}$ dan Susi Machdalena ${ }^{2}$ \\ ${ }^{1,2}$ Fakultas Ilmu Budaya, Universitas Padjadjaran \\ Jalan Raya Bandung-Sumedang KM 21, Jatinangor, Sumedang, Indonesia \\ ${ }^{1}$ Corresponding email: irzam19001@mail.unpad.ac.id \\ ${ }^{2}$ Email: machdalena@unpad.ac.id
}

Received: 14 December 2020 Accepted: 28 February 2021 Published: 1 June 2021

\begin{abstract}
Chanoyu is a popular culture today even though this culture has been around for a long time. This study aimed to describe the problem of terms, especially their relationship with the culture of the speakers in the chanoyu procession. This research was a qualitative descriptive study. The approach used was an ethnolinguistic approach. The result of this research showed that the tea ceremony has become an important part of Japanese culture. The terms found in the procession indicate that the guest and the host respect each other and give meaning to the journey of life. The use of terms in the lexicon in the tools used is also seen in terms of form, its manufacture and use creates perfect harmony in the chanoyu process.
\end{abstract}

Keywords: Chanoyu, ethnolinguistic, tea, ceremony

\begin{abstract}
Abstrak: Chanoyu merupakan budaya yang populer saat ini meskipun budaya ini sudah ada sejak dulu. Artikel ini bertujuan untuk mendeskripsikan persoalan istilah-istilah terutama hubungannya dengan budaya penuturnya dalam prosesi chanoyu. Artikel ini merupakan penelitian deskriptif kualitatif. Pendekatan yang digunakan adalah pendekatan etnolinguistik. Hasil dari penelitian ini adalah upacara minum teh telah menjadi bagian penting bagi kebudayaan Jepang. Istilah-istilah yang ditemukan dalam prosesinya menunjukkan bahwa antara tamu dan tuan rumah saling menghormati dan memberi makna mengenai perjalanan hidup. Penggunaan istilah pada leksikon dalam peralatan yang digunakan juga terlihat dari sisi bentuk, pembuatan, dan kegunaannya menciptakan harmoni yang sempurna pada proses chanoyu tersebut.

Kata kunci: Chanoyu, etnolinguistik, teh, upacara
\end{abstract}

\section{To cite this article:}

Sarif S., I., \& Machdalena, S. (2021). Istilah-Istilah dalam Upacara Minum Teh Jepang Chanoyu (Suatu Kajian Etnolinguistik). Diglosia: Jurnal Kajian Bahasa, Sastra, dan Pengajarannya, 4(2), 127-138. https://doi.org/10.30872/diglosia.v4i2.154 


\section{A. PENDAHULUAN}

Jepang adalah negara yang sangat kaya dan memiliki beragam budaya. Salah satu keragaman budayanya yang paling terkenal di Jepang hingga saat ini adalah budaya minum. Budaya yang diwariskan secara turun temurun ini menggunakan bahan alami seperti beras, daun teh, dan umbi-umbian dari hasil pertanian Jepang, kemudian diproduksi secara alami tanpa bahan pengawet dan juga jauh lebih sederhana dan lebih tradisional. Bentuk minuman tradisional yang paling populer di Jepang saat ini adalah ocha atau teh.

Teh sebenarnya merupakan salah satu minuman yang paling digemari di Jepang. Meski begitu, banyak orang yang belum memahami teh secara keseluruhan. Menyeduh teh merupakan hal yang mudah dengan hanya menyeduh air panas. Namun, di balik kesederhanaannya ini membuat teh itu menjadi istimewa. Jadi, di setiap daerah memungkinkan tercipta beberapa budaya teh yang menjadi milik negara tertentu, yang beradaptasi dengan adat istiadat masyarakat, dan membangun budaya minum teh yang berbeda (Kastuti, 2020). Di beberapa negara, terdapat berbagai macam cara minum teh, termasuk di Indonesia yang biasanya teh berada di banyak daerah. Kebiasaan minum teh berbeda dari satu daerah ke daerah lain, dan tidak ada upacara minum teh yang rumit di Indonesia, seperti di Cina atau Jepang. Hal ini yang dijelaskan oleh Serad (2016) bahwa daerah yang berbeda memiliki praktik dan kebiasaan berbeda yang terkait dengan teh. Namun upacara minum teh dengan upacara yang relatif lama, memiliki keunikan tersendiri baik dari segi proses dan alatnya adalah Chanoyu berasal dari Jepang.

Jika ditinjau dari karakter huruf pembentukan kanjinya, Chanoyu terdiri dari huruf $c h a$ (茶) artinya teh, no (の) sebagai partikel penghubung, dan $y u$ (湯) air hangat atau air panas. Arti kata chanoyu secara harafiah adalah "air panas untuk teh". Chanoyu juga mempunyai nama lain yakni chado (茶道) artinya "cara pembuatan teh", namun kemudian berkembang lebih luas menjadi upacara minum teh dalam tradisi Jepang hingga sekarang ini.

Pada Zaman Heian (794-1185) teh yang masuk ke negeri Jepang adalah teh cokelat yang hanya berfungsi sebagai obat. Namun saat itu, teh masih sangat sedikit jumlahnya. Kemudian, teh hijau mulai masuk bersama Buddha, yang dibawa oleh Eisai, seorang pendeta penyebar agama zen, selama zaman Kamakura (1185-1333). Teh menjadi semakin dikenal seiring dengan penyebaran agama Buddha di Jepang, dan Sen no Rikyu, figur bersejarah dengan pengaruh yang paling banyak terhadap chanoyu, memperkenalkan upacara minum teh secara meluas pada abad ke-16. Sen no Rikyu, menerapkan ide ichi-go-ichi-e, mengikuti gurunya pada bidang teh, Takeno Jōō. Upacara minum teh dengan konsep baru juga dikembangkan secara luas olehnya. Nilai-konsep tersebut adalah 和 (wa atau harmoni), 敬 (kei atau hormat), 清 (sei atau kemurnian, kebersihan), 寂 (jaku atau ketenangan).

Sejak saat Rikyū memperkenalkan konsepnya itu kemudian dikenal sebagai tokoh yang telah berhasil membawa jiwa kesederhanaan dalam setiap ritual minum teh yang ia bawakan, yang disebut dengan wabicha. Untuk mempertahankan pemikiran tersebut, Rikyū berhasil membuat chanoyu tetap eksis sampai sekarang (Fajria, 2015).

Chanoyu mengangkat tugas sederhana menyiapkan minuman bagi tamu menjadi sebuah karya seni, rangkaian gerakan rumit yang dilakukan dalam urutan ketat dan dihargai oleh penerimanya. Upacara minum teh atau, terjemahan harfiahnya "aliran 
teh" dalam banyak hal merupakan mikrokosmos tradisional Jepang omotenashi, yang diterjemahkan menjadi melayani tamu dengan sepenuh hati. Lan (1962, p. 165) mendefinisikan upacara minum teh sebagai suatu permainan yang halus agar orangorang yang tertarik dengan seni kehidupan. Seni kehidupan yang dimaksud adalah bagaimana melatih kesabaran serta ketelatenan dalam berperilaku sehari-hari agar dapat meraih ketenangan dalam diri sendiri.

Budaya merupakan ciri khas suatu negara sebagai identitasnya. Kita tidak mungkin memisahkan budaya dari kosakata yang digunakan dalam budaya tersebut (Wahyuni, 2017). Saat ini, jika tidak ada bahasa, peradaban bahkan bisa mati. Ini menyiratkan bahwa bahasa dan budaya adalah satu rumpun yang sulit untuk dilepaskan. Karena dua mekanisme, budaya atau tradisi tercipta dan akan terus ada. Mekanisme pertama sebagai konsekuensi hubungan manusia dengan lingkungannya. Selanjutnya, bagaimana manusia membangun budayanya merupakan mekanisme kedua. Oleh karena itu, budaya dapat diartikan sebagai tafsir manusia terhadap simbol yang dapat diwariskan dari generasi ke generasi dan merupakan alat untuk kehidupan sosial.

Hal yang paling fundamental tentang relasi bahasa dan kebudayaan adalah bahasa yang harus dipelajari dalam konteks kebudayaan dan sebaliknya kebudayaan dapat dipelajari melalui bahasa. Dalam hal ini, kajian yang dapat mempelajari keduanya adalah ilmu antropolinguistik atau etnolinguistik: antropologi sebagai ilmu yang mempelajari tentang manusia dan linguistik mempelajari tentang bahasa. Sudaryanto (1996, p. 7) mengemukakan bahwa "etnolinguistik adalah ilmu yang meneliti seluk-beluk hubungan aneka pemakaian bahasa dengan pola kebudayaan".

Hymes juga ikut mendefinisikan bahwa bahasa dan etnografi memiliki relasi yang sangat erat (Wardhaugh, 2006, p. 249). Etnografi mendeskripsikan struktur sosial, aktivitas masyarakat, sumber material dan simbolik yang menggambarkan kondisi masyarakat tertentu. Dalam hal ini, bahasa menjadi sumber penting untuk diamati, terutama bagaimana bahasa digunakan dalam aktivitas kemasyarakatan, bagaimana bahasa digunakan dalam ritual keagamaan, bagaimana bahasa juga digunakan dalam budaya. Inilah yang melatarbelakangi munculnya kajian antropolinguistik atau yang lebih populer kajian etnolinguistik.

Kajian etnolinguistik dalam area linguistik sendiri sudah dilakukan oleh beberapa peneliti. Sebagai contoh, penelitian etnolinguistik dalam ranah linguistik dan antropologi budaya dilakukan oleh Pratiknyo (2009) melakukan kajian tentang istilah-istilah upacara perkawinan adat Jawa bubak kawah dan tumplak punjen di Kecamatan Bendosari, Kabupaten Sukoharjo.

Penelitian lainnya dilakukan oleh Suryawati (2018) dengan judul "Cerminan Jiwa Chanoyu dalam Pepatah Zen yang Terdapat pada Kakejiku". Penelitian Suryawati bertujuan untuk mendeskripsikan makna jiwa chanoyu yang tercermin dalam pepatah bijak Zen pada kakejiku. Dari hasil penelitian didapatkan bahwa jiwa chanoyu $W a$ tercermin pada pepatah gankokusaishou (篇谷栽松) dan kanzashite shoufuwo kiku (閑坐聴松風) mengenai keharmonisan antara manusia dengan manusia, manusia dengan lingkungan yang ditujukan untuk Sang Pencipta, juga harmoni dengan diri sendiri sebagai bentuk penemuan jati diri.

Istilah dalam prosesi upacara teh atau chanoyu dapat ditinjau dari segi makna leksikalnya. Menurut Djajasudarma (1993, p. 13), "makna leksikal adalah makna kata-kata yang dapat berdiri sendiri, baik dalam bentuk tuturan maupun dalam bentuk kata dasar". Selain itu, Kridalaksana (2011, p. 149) juga memaparkan bahwa 
"makna leksikal adalah makna unsur-unsur bahasa sebagai lambang benda, peristiwa, dan lain-lain". Di samping makna leksikal dari istilah chanoyu, juga dapat dilihat dari sisi makna kulturalnya. Makna kultural adalah makna bahasa yang dimiliki oleh masyarakat dalam hubungannya dengan budaya tertentu. Makna kultural diciptakan dengan menggunakan simbol-simbol yang menjadi bagian keseharian dari masyarakat penuturnya.

Oleh karena itu, penelitian yang dilakukan ini mendeskripsikan persoalan kebahasaan terutama hubungannya dengan budaya penuturnya, sehingga pada penelitian ini lebih lanjut dikaji mengenai istilah-istilah upacara minum teh atau Chanoyu dengan pendekatan etnolinguistik.

\section{B. METODE}

Penelitian ini bersifat deskriptif kualitatif, yakni mendeskripsikan data kebahasaan yang berkaitan dengan Chanoyu, yang kemudian dianalisis berdasarkan makna leksikal dan makna kulturalnya. Deskriptif artinya memeriksa gejala-gejala secara cermat dan teliti berdasarkan fakta-fakta kebahasaan yang hidup dalam masyarakat penuturnya. Penelitian ini mendeskripsikan masalah yang ada, yaitu tentang istilah-istilah yang digunakan dalam upacara minum teh Chanoyu. Sejalan dengan metode penelitian yang digunakan juga kajian yang memayungi penelitian ini adalah bahasa dan kebudayaan, maka pendekatan yang digunakan dalam adalah pendekatan etnolinguistik.

Untuk dapat mendeskripsikan suatu masalah dengan tepat dan akurat, maka sebagai pendukung peneliti menggunakan studi kepustakaan sebagai cara pengumpulan data, yaitu mengumpulkan data melalui peninggalan tertulis, terutama berupa arsip-arsip dan termasuk juga buku-buku tentang pendapat, teori, dan lainlain yang berhubungan dengan masalah penelitian, dan kemudian dianalisis dan dirangkum ke dalam tulisan ini. Sumber data lainnya diambil melalui media elektronik internet yang memunculkan berbagai situs yang berhubungan dengan Wagashi. Analisis data dilakukan beberapa tahap. Tahap pertama, data akan diklasifikasi dan dideskripsikan dari segi bentuk lingual. Kedua, menjelaskan leksikon yang mencerminkan kultural dan makna simbolik sebagai nilai kearifan lokal pada Chanoyu dengan menggunakan pendekatan etnolinguistik. Terakhir, menarik simpulan.

\section{PEMBAHASAN}

Dalam kajian Etnolinguistik, kebudayaan Jepang dapat dikatakan unik karena kebudayaan Jepang selalu menekankan pada unsur estetis yang dikaitkan dengan makna filosofis. Seperti huruf-huruf kanji Jepang yang ditulis secara arbitrer, namun mengandung makna dibalik kanji tersebut. Karakter kanji tersebut juga tak dapat dipisah dari upacara teh dianggap sebagai suatu hal yang sakral dan menjadi suatu simbol dari komunikasi manusia yang ideal terhadap kekuatan kosmik dalam penataan ideal, yang diterapkan dalam realitas dunia kita dengan melakukan upacara teh (Plutschow, 1999). Pada bagian ini peneliti membagi dua bagian dari hasil temuan istilah-istilah Chanoyu, pertama berdasarkan prosesi ritual. Kedua berdasarkan alat-alat atau benda yang digunakan selama prosesi itu. Berikut pengklasifikasian dan pemaparan data yang ditemukan. 


\section{Prosesi Ritual Chanoyu}

Para tamu akan datang beberapa saat sebelum upacara dimulai kemudian memasuki ruang tunggu. Sebelum masuk, tuan rumah juga harus mempersiapkan diri dengan pemusatan pikiran dan hal-hal detail dalam persiapan alat. Para tamu akan disuguhi air panas, seperti sakurayuu 桜湯 (teh sakura). Leksikon ini terdiri dari dua kanji yaitu sakura 桜 dan yu 湯. Kanji pertama berarti bunga sakura dan kanji kedua berarti air panas. Bunga sakura memiliki aroma yang harum sehingga bagi masyarakat Jepang, bunga sakura dapat membuat perasaan menjadi bahagia dan tenteram (Yuwana, 2010). Setelah tamu tiba dan persiapan selesai, para tamu menunggu sebelum tuan rumah memanggil nama-nama para tamu. Hal tersebut dilakukan supaya tamu yang datang dapat menikmati teh dengan perasaan yang tenang dan menyenangkan. Semua itu dilakukan sesuai dengan salah satu ajaran yang terdapat dalam chanoyu yaitu ichigo ichie「一期一会」 yang bermakna, hanya ada satu kesempatan dalam seumur hidup. Oleh karena itu, peristiwa ini harus benarbenar dihargai. Kalimat tersebut dapat dikatakan sebagai bentuk pelayanan yang baik (Nute, 2019).

Setelah dipanggil, para tamu akan langsung bertemu dengan tuan rumah dan memberikan penghormatan (membungkukkan badan) kepada tuan rumah yang lebih dikenal dengan istilah ojigi. Ojigi pada tradisi Jepang merupakan etika dan tata krama yang sudah ada sejak dulu dan telah menjadi satu jiwa dengan perilaku orang Jepang. Hal ini tidak mengherankan jika Jepang adalah bangsa yang menjunjung etika dan tata krama kepada siapa pun. Ojigi memperlihatkan gerakan indah pada tubuh saat membungkukkan badan. Di antara banyaknya jenis ojigi yang ada, Zarei 座礼 merupakan jenis ojigi yang dilakukan pada upacara ini. $Z a$ 座 artinya duduk dan rei 礼 artinya penghormatan yang merupakan gaya berlutut hingga saling menundukkan kepala dan tidak menyentuh tanah (Takeda, 2017).

Seorang profesional chanoyu akan menyiapkan teh dan memberikan chawan atau cangkir kepada para tamunya (untuk laki-laki biasanya diberi yang simpel sedangkan wanita diberi chawan bermotif bunga). Tamu duduk dengan dada yang tegap dan kedua kaki dilipat ke belakang. Cara duduk ini disebut Seiza 正座 (Ukita, 2020) yang merupakan cara formal dan sopan ketika duduk di rumah tradisional Jepang yang berlantaikan tatami. Ini perlu diterapkan untuk menjunjung tinggi nilai kesopanan yang kuat serta simbol permintaan maaf layaknya menyerahkan diri di hadapan tuan rumah.

Chawan diambil lalu diletakkan di telapak tangan kiri dan tangan kanan harus memutar cangkir 180 derajat dalam tiga putaran sebelum menempelkan cangkir ke bibir. Tamu dianggap kurang sopan dan tuan rumah akan tersinggung jika tamu tidak melakukan hal ini. Hal ini dikarenakan motif bunga-bunganya harus terlihat jelas ke depan sehingga tuan rumah dan orang-orang yang hadir mengetahui bahwa tamu sungguh menikmati teh dan juga dapat menikmati keindahan dari gambar cangkir tersebut. Tamu harus menghabiskan tegukan terakhir ketika teh hampir habis dengan cara membuat suara seperti menyeruput dengan tujuan agar teh itu terdengar sangat dinikmati. Ujung cangkir harus dilap dengan tangan kanan. Kemudian, memutar cangkir berlawanan arah jarum jam sebelum mengembalikannya kepada tuan rumah (Yuwana, 2010). 


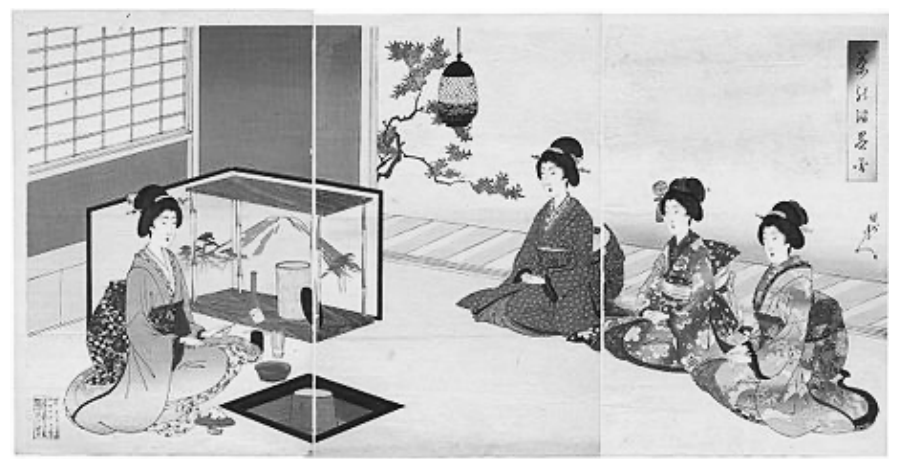

Gambar 1. Sketsa prosesi Chanoyu

(Sumber: https://en.wikipedia.org/wiki/Japanese_tea_utensils)

\section{Peralatan Chanoyu}

Perjamuan upacara teh didasarkan pada tema yang berbeda. Kesenangan dan kenyamanan bagi para tamu adalah hal yang utama untuk merenungkan tema apa yang telah dipilih tuan rumah. Tuan rumah harus mempertimbangkan secara khusus dalam menyatukan perlengkapan yang akan mencerminkan ide tema upacara tersebut. Misalnya, jika perjamuan diadakan pada musim panas, tuan rumah akan menawarkan tema yang lebih sejuk. Misalnya, memilih chawan atau mangkuk teh dangkal dan sendok teh dengan tema seperti "embun" akan bisa membantu para tamu merasa sejuk.

Suasana upacara perjamuan minum teh juga menentukan tema yang akan dipakai. Pertemuan secara formal biasanya cenderung lebih tenang, temanya mungkin lebih kompleks sehingga para tamu dapat meluangkan waktu mereka untuk merenung sepanjang hari. Sebaliknya, pertemuan informal lebih langsung dan menunjukkan hati yang puitis dan ceria. Tuan rumah menyatukan berbagai peralatan yang berbeda dalam bentuk, ukuran, warna, dan bahan untuk mencoba menciptakan harmoni yang sempurna. Namun, kebanyakan dari alat yang digunakan merupakan peralatan teh yang dibuat secara tradisional. Berikut merupakan temuan istilah-istilah peralatan pada chanoyu yang didukung oleh sumber Gensitsu (2007).

\section{a. Chasitsu (茶室)}

Chashitsu dalam tradisi Jepang adalah ruang arsitektur yang dirancang digunakan untuk upacara minum teh (chanoyu). Leksikon ini terdiri dari 2 karakter yaitu cha 茶 yang artinya teh dan sitsu 室 yang artinya ruangan. Ciri khas chashitsu adalah jendela shoji atau pintu geser yang terbuat dari kisi-kisi kayu yang ditutupi oleh kertas Jepang yang tembus cahaya; lantai tikar tatami; sebuah ceruk tokonoma (sebidang ruang yang menjadi titik pusat di dalam sebuah ruangan); serta warna dan gaya yang sederhana dan lembut. Ukuran dasar chashitsu yang ideal adalah 4,5 tatami tikar. 


\section{b. Tatami (畳)}

Tatami (secara harfiah berarti "lipat dan tumpuk") adalah semacam tikar yang berasal dari Jepang yang dibuat secara tradisional, Tatami dibuat dari jerami yang sudah ditenun, namun saat ini banyak Tatami dibuat dari styrofoam. Tatami mempunyai bentuk dan ukuran yang beragam yang rata-ratanya $910 \mathrm{~mm} \times 1.820$ $\mathrm{mm}$, dan sekelilingnya dijahit dengan kain brokade atau kain hijau yang polos. Karena tatami terbuat dari jerami, tikar ini tidak hanya memberikan keindahan dalam rumah, tapi juga membantu untuk tetap hangat selama musim dingin di Jepang.

\section{c. Chawan (茶碗)}

Chawan (mangkuk teh) adalah mangkuk kecil yang digunakan untuk meminum teh. Terdapat berbagai ukuran dan bentuk. Mangkuk dengan dasar yang rendah digunakan untuk musim panas agar teh cepat dingin, sedangkan pada musim panas akan digunakan mangkuk dengan dasar yang dalam (Suryawati, 2018).

\section{d. Chaki/natsume (茶器 - 菓)}

Chaki atau natsume merupakan bak tempat penyimpanan bubuk teh hijau. Nama item ini pada dasarnya chaki, tetapi nama natsume juga digunakan karena ada wadah teh tertentu yang bentuknya mirip buah plum yang memiliki bagian bawah lebih kecil daripada bagian atasnya dan berwarna coklat kemerahan.

\section{e. Chasen (茶笔)}

Chasen adalah pengocok teh dari bambu yang digunakan untuk persiapan pembuatan teh. Mereka diukir dengan tangan dari sebatang bambu. Bergantung pada jenis bambu mereka dibuat dari bentuk ruas, jumlah ruas, ketebalan bambu, panjang bambu, warna benang yang dianyam di sekeliling pangkal taring, dan sebagainya.

\section{f. Hishaku (柄构)}

Adalah sendok bambu panjang dengan bintil di sekitar bagian tengah pegangannya. Ini digunakan untuk menuangkan air panas dari ceret (kama) ke dalam mangkuk teh dan bila sesuai, untuk memindahkan air dingin dari wadah air bersih ke panci besi. Tetsubin (ketel besi) tidak membutuhkan hishaku. Untuk berbagai upacara dan musim yang berbeda, jenis yang berbeda digunakan. Untuk upacara pembilasan tangan dan mulut oleh para tamu sebelum memasuki ruang teh, atau untuk digunakan oleh tuan rumah di area persiapan belakang ruang teh (mizuya), versi yang lebih besar yang terbuat dari kayu cemara dikenal sebagai mizuya-bishaku.

\section{g. Chashaku (茶枸)}

Leksikon ini terdiri dari dua karakter kanji yaitu cha 茶 dan shaku 枃. Kanji pertama artinya teh dan kanji kedua artinya sendok besar Sering disebut sendok teh, chashaku digunakan untuk memindahkan teh bubuk dari wadah teh (chaki) ke cangkir teh (chawan). Sendok teh pada chanoyu biasanya terbuat dari bambu yang sempit dan tipis, meskipun yang terbuat dari kayu atau gading juga tersedia. Panjangnya sekitar 18 sentimeter (panjang 7,1 secara umum. Bahan asli yang dikirim dari Cina ke Jepang adalah gading. Secara tradisional, ahli teh di Jepang telah mengukir chashaku bambu mereka sendiri, memberi mereka tabung penyimpanan bambu (tsutsu) serta 
nama puitis (mei 銘) yang juga terukir di tabung penyimpanan. Ini akan sangat bergantung pada nama puitisnya untuk memilih chashaku untuk digunakan pada pertemuan chanoyu.

\section{h. Mizusashi (水指)}

Mizusashi adalah wadah berpenutup yang digunakan selama upacara oleh tuan rumah di ruang teh untuk air dingin segar. Air di akhir upacara biasanya digunakan untuk mengisi air di kama. Mizusashi biasanya terbuat dari keramik, tetapi mizusashi dari kayu, kaca, dan logam juga digunakan.

\section{i. Chabako (茶箱)}

Leksikon ini terdiri dari dua karakter kanji yaitu cha 茶 artinya teh dan hako 箱 artinya kotak. Kotak berpenutup khusus berisi cangkir teh, wadah teh, sendok teh, dan peralatan lainnya. Alat-alat tersebut merupakan perangkat pembuat teh untuk perjalanan luar ruangan dan pembuatan teh, dan tersedia dalam berbagai jenis. Kotak teh terbuat dari kayu, dan mungkin dipernis dan dihias, atau dibiarkan tanpa perawatan. Dalam prosedur pemakaiannya pada upacara teh, kotak dibawa ke tempat di mana teh akan dibuat, sering kali di atas nampan dan upacara berlanjut dengan setiap benda dikeluarkan dari kotak dan terakhir akan dikembalikan lagi dalam kotak.

\section{j. Kama (釜)}

Kama atau ceret digunakan untuk memanaskan air. Kama diletakkan di atas kompor arang yang disebut furo, dalam tungku yang terletak di atas lantai di ruang minum teh Jepang. Ada dua jenis kama, yaitu untuk musim panas dan musim dingin. Ada banyak bentuk dan tekstur yang berbeda pada kama, tetapi yang paling penting adalah kualitas dari suara yang ditimbulkan pada saat air mulai mendidih.

\section{k. Furo (風炉)}

Di ruang teh, furo adalah pemanggang portabel yang digunakan untuk memanaskan ketel air panas (kama) untuk membuat teh. Leksikon ini terdiri dari dua karakter kanji yaitu $f u$ 風 artinya angin dan ro 炉 artinya pemanas. Sementara contoh langka dari furo kayu juga tersedia, mereka biasanya terbuat dari keramik atau logam.

\section{1. $R o$ (炉)}

Ro adalah lubang api yang dibangun di lantai ruang teh dan digunakan untuk memanaskan ketel air panas (kama) untuk membuat teh di musim dingin. Robuchi ( 炉縁) (kerangka ro) adalah bingkai yang dipasang di sekelilingnya di bagian atas dan biasanya terbuat dari kayu berpernis. Rangkanya dilepas dan ro ditutup dengan salah satu tikar tatami yang membentuk permukaan lantai selama musim saat ro tidak digunakan, dan tidak terlihat.

\section{m. Kensui (建水)}

Kensui adalah istilah untuk wadah air bilas yang digunakan oleh tuan rumah di ruang teh. Biasanya terbuat dari metal atau keramik. Air yang telah digunakan untuk membilas mangkuk teh dibuang dan dimasukkan ke dalamnya. Alat ini dijauhkan 
dari pandangan para tamu sejauh mungkin dan menjadi barang terakhir yang dibawa ke ruang teh. Meskipun kensui adalah item yang diperlukan untuk upacara minum teh, namun bukan barang "pameran" yang diharapkan secara khusus diperhatikan oleh para tamu.

\section{n. Tetsubin (鉄瓶)}

Tetsubin terdiri dari dua karakter kanji yaitu tetsu 鉄 yang artinya besi dan bin 瓶 yang artinya kendi atau ketel besi memiliki cerat dan pegangan tuang yang melintang di atas wadah besi. Selama beberapa upacara minum teh, alat ini digunakan untuk memanaskan dan menuangkan air panas.

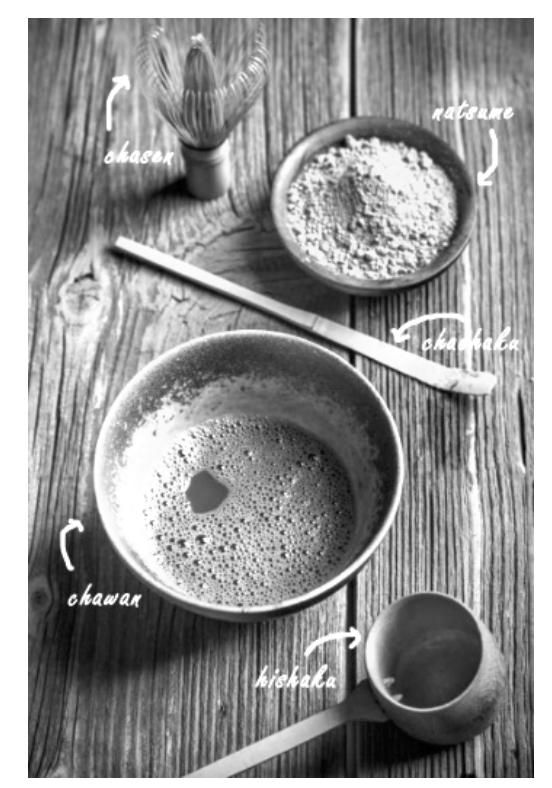

\section{Gambar 2. Beberapa peralatan Chanoyu seperti chasen, natsume, chasaku, chawan, hishaku berturut-turut.}

(Sumber: https://jic.co.id/chanoyu-2)

\section{PENUTUP}

Dengan sejarah yang merentang lebih dari seribu tahun, upacara minum teh telah menjadi bagian penting bagi kebudayaan Jepang. Banyak makna kehidupan dimasukkan dalam upacara minum teh di Jepang, utamanya istilah-istilah dari karakter di setiap prosesi dalam upacara minum teh di Jepang yang mengandung arti. Istilah-istilah dalam prosesi chanoyu yang dilakukan antara tamu dan tuan rumah mencerminkan rasa saling hormat dan tamu harus dihargai oleh semua orang sejak dulu hingga saat ini. Istilah atau nama yang melekat pada peralatan yang digunakan pada chanoyu juga menunjukkan bentuk kearifan lokal masyarakat Jepang yang terlihat dari sisi bentuk, pembuatan dan kegunaan yang dipilih secara bebas oleh tuan rumah tergantung pada musim dan tamu yang hadir. Tuan rumah juga menyatukan berbagai peralatan yang berbeda dalam bentuk, ukuran, warna, dan bahan untuk mencoba menciptakan harmoni yang sempurna. 
Istilah secara simbolik yang terdapat dalam prosesinya juga mengisyaratkan bahwa upacara minum teh itu sifatnya sakral. Itu juga sekaligus menggambarkan bahwa "yang penting bukan ketika teh dihirup melainkan bagaimana proses membuatnya". Dalam proses pembuatan teh lalu menghidangkannya dengan aturan yang gemulai alami membuat kita teringat "diri", teringat alam, dan juga teringat perjalanan hidup.

\section{DAFTAR PUSTAKA}

Djajasudarma, T. F. (1993). Metode Linguistik: Ancangan Metode Penelitian dan Kajian. Bandung: Eresco.

Genshitsu, S. (2007). A Chanoyu Vocabulary: Practical Terms for the way of tea [Eigo-ban Jitsuyō Chadō Yogo Jiten]. Vol. 1. Kyoto-shi: Tankosha.

Kastuti, T. I., \& Permatasari, C. D. (2020). Comparative Study of Chanoyu Tea and Tea Serving in Yogyakarta Palace. Izumi, 9(2), 166-175. https://doi.org/10.14710/izumi.9.2.166-175

Kridalaksana, H. (2011). Kamus Linguistik. Jakarta: Gramedia Pustaka Utama.

Lan, N. J. (1962). Djepang Sepandjang Masa. Jakarta : PT. Kinta.

Fajria, N. (2015). Kesederhanaan Wabicha dalam Upacara Minum Teh Jepang. Izumi, 5(1), 37-43. $\quad$ Retrieved from http://library1.nida.ac.th/termpaper6/sd/2554/19755.pdf

Nute, K. (2019). Buildings as a Means to Intersubjectivity: Case Studies from Traditional Japanese Architecture. The International Journal of the Constructed Environment, 10(3), 1-9. https://doi.org/10.18848/2154-8587/cgp/v10i03/1-9

Plutschow, H. (1999). An Anthropological Perspective on the Japanese Tea Ceremony. Anthropoetics: The Joumal of Generative Anthropology, 5(1). Retrieved from http://anthropoetics.ucla.edu/ap0501/tea/

Pratiknyo, A. (2009). Istilah-Istilah Upacara Perkawinan Adat Jawa Bubak Kawah Dan Tumplak Punjen di Kecamatan Bendosari Kabupaten Sukoharjo (Suatu Kajian Etnolinguistik). Universitas Sebelas Maret. Retrieved from https://digilib.uns.ac.id/dokumen/download/14889/Mjk3NjA=/Istilahistilah-upacara-perkawinan-adat-jawa-Bubak-Kawah-dan-Tumplak-Punjen-diKecamatan-Bendosari-Kabupaten-Sukoharjo-3922b.pdf

Serad, S. H. (2016). Leaf it to Tea. Jakarta: Afterhours Books.

Sudaryanto. (1996). Linguistik: Identitasnya, Cara Penanganan Obyeknya, dan Hasil Kajiannya. Yogyakarta: Duta Wacana University Press.

Suryawati, C. T. (2018). Cerminan Jiwa Chanoyu dalam Pepatah Zen yang Terdapat pada Kakejiku. Jurnal Ayumi, 5(1), 52-67. Retrieved from https://ejournal.unitomo.ac.id/index.php/ayumi/article/view/826

Takeda, T., Kamagahara, Y., Yu, X., Kida, N., Hara, T., \& Ota, T. (2017). Effect of Japanese Style Bowing on the Perception of the Person Receiving the Greeting. Transactions of Japan Society of Kansei Engineering, 16(1), 67-73. https://doi.org/10.5057/jjske.tjske-d-16-00043

Ukita, R., \& Diaz, J. A. (2020). Flexions of the Popliteal Artery and the Culture Could Challenge the Outcomes of the Endovascular Procedures. Annals of Vascular Diseases, 13(1), 1-3. https://doi.org/10.3400/avd.edit.19-00135 
Wahyuni, T. (2017). Makna Kultural pada Istilah Bidang Pertanian Padi di Desa Boja, Kabupaten Kendal, Jawa Tengah (Sebuah Tinjauan Etnolinguistik). Jalabahasa, 13(1), 20-30. https://doi.org/10.36567/jalabahasa.v13i1.48

Wardhaugh, R. (2006). An introduction of Sociolinguistics. USA: Blackwell Publishing. Yuwana, C. (2010). Makna Sakura bagi Masyarakat Jepang. Parafrase, 10(1). Retrieved from
sby.ac.id/index.php/parafrase/article/view/156 http://jurnal.untag- 
